\title{
The Electrical Motorcycle Charger for Application in a Residence
}

\author{
Chaiyan Jettanasen ${ }^{1, *}$, and Chaichan Pothisarn ${ }^{1}$ \\ ${ }^{1}$ Faculty of Engineering, King Mongkut's Institute of Technology Ladkrabang, Bangkok, 10520, Thailand
}

\begin{abstract}
The aim of this paper is to design the charger for an electric motorcycle and analyze the behavior of voltage and current value during charging. The AC voltage supply from a residence is converted to DC voltage to charge the energy storage system by controlling the voltage and current values suitable for the charge process in all periods. The designed charger is based on the principle of a buck converter with using constant current and constant voltage technique in order to charge a $12 \mathrm{~V}, 21$ Ah lead-acid battery inside the electric motorcycle. By considering the results, the first state of battery charging is a constant current mode by using the current of $5 \mathrm{~A}$ with the initial voltage of $55 \mathrm{~V}$. In the second mode, the battery charging is done by constant voltage of $72 \mathrm{~V}$ and the current is reduced until the battery is full. Moreover, the charging time is about 6-8 hours.
\end{abstract}

\section{Introduction}

In recent years, all transportation requires a large number of fuels in both oil and natural gas types, resulting in environmental pollution. However, the amount of fuel has a trend to decrease while the use of vehicles and motorcycles is increased. As a result, the costs of oil and natural gas are high. For this reason, the accelerating growth of electric vehicles is widespread due to its no pollution, since electrical energy can be produced from renewable energy, i.e. solar, wind, and so on. As a rule, the energy in an electric vehicle relies upon an energy storage system and a motor - it does not burn internal combustion engine, hence no a pollution problem. If the energy storage system is exhausted, it will be charged by electricity. However, there are some disadvantages of using an electric vehicle, which is the limitation of provisional distance. If an electric vehicle needs to take more distance, the large energy storage system will be required leading to an increase in weight. In addition, the charge of the large energy storage system necessitates taking long periods.

The traditional electrical vehicle battery charger mainly consists of DC/DC and DC/AC stages [1]. The $\mathrm{DC} / \mathrm{DC}$ converter acting as the $\mathrm{DC} / \mathrm{DC}$ stage is used to boost the voltage towards the desired level, while the $\mathrm{DC} / \mathrm{AC}$ stage acting as an inverter is mainly to change the DC energy from the battery to AC energy for various loads. A battery charger usually utilizes a boost converter at the first stage and a dc-dc converter regulates the output voltage at the second stage as designed battery chargers in [2] and [3]. The doublestage system needs more semiconductors and complex multiple-loop control structures, resulting in the complicated design, low power density and conversion efficiency [4-5]. To solve these problems, a novel electrical vehicle charger that can boost the battery voltage and output $\mathrm{AC}$ voltage with only one-stage power conversion is proposed in [6].

There are many research articles investigating various topologies and control strategies for battery charger, i.e. PR controllers to regulate the utility line current [7], single-phase, three-wire charger with unbalanced current compensation [8], single-phase charger with power angle control [9], three-phase offboard charger with boost rectifier [10], and single-phase two-stage bidirectional EV charger [11]. In this paper, the battery charger for an electric motorcycle is proposed. The AC voltage supply from a residence is converted to DC voltage to charge the electric motorcycle by controlling the voltage and current values suitable for the charge process in all periods. The designed charger is based on the principle of a buck converter with using constant current and constant voltage technique.

\section{Experimental setup design}

In this section, the charger for an electric motorcycle is designed which is based on the principle of a buck converter. The energy storage system in the electric motorcycle is consist of five sets of a $12 \mathrm{~V}, 21$ Ah leadacid battery. In order to charge the electric motorcycle, the charger typology is divided into two parts: a power circuit and a control circuit as shown in Fig. 1(a) and (b) respectively.

\subsection{The power circuits}

\subsubsection{The transformer of a power circuit}

Since the voltage received from a power supply is high, leading to electrical appliances inside the circuit cannot withstand the high voltage and the control of the

Corresponding author: kjchaiya@staff.kmitl.ac.th 
microcontroller is difficult. A transformer is used as a voltage converter. The high voltage needs to be reduced by using a 2 to 1 voltage transformer which converts the voltage from $220 \mathrm{~V}$ to $110 \mathrm{~V}$.

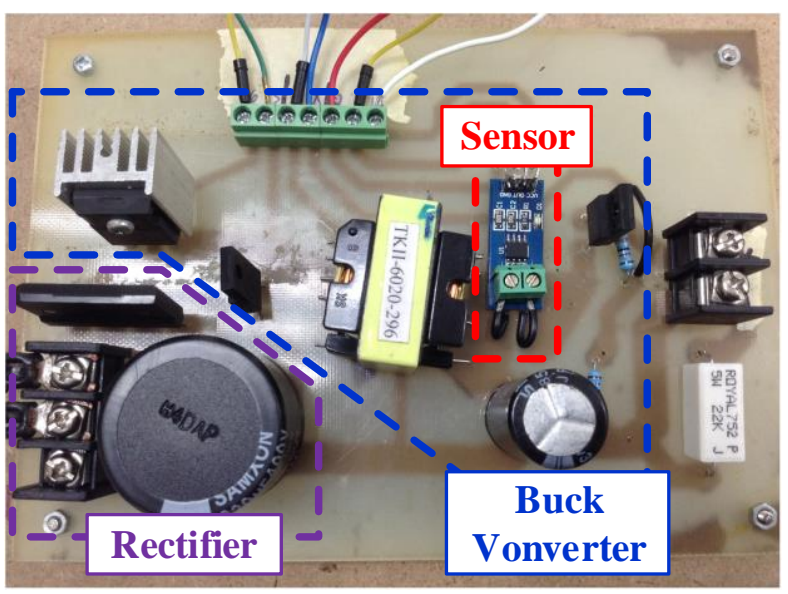

(a) Power circuit

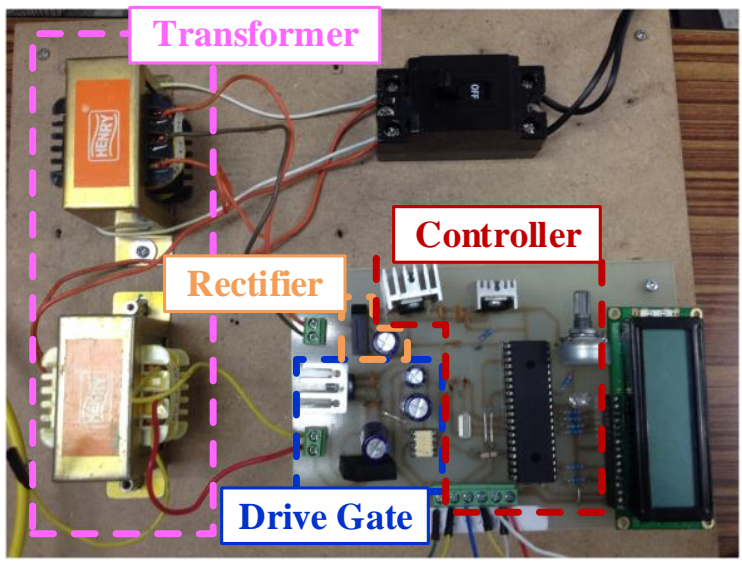

(b) Control circuit

Fig. 1. The charger typology for an electric motorcycle.

\subsubsection{Rectifier of a power circuit}

The rectifier is used to convert alternating current (AC) to direct current (DC) to charge batteries. The Silicon Bridge rectifier of RBV2500D - RBV2510D is used to convert the $\mathrm{AC}$ voltage of $110 \mathrm{~V}$ from the transformer into DC voltage of $155 \mathrm{~V}$. A $330 \mu \mathrm{F}$ capacitor is employed to reduce the ripple from the bridge rectifier signal to provide DC voltage with constant values as shown in Fig. 2.

\subsubsection{Buck converter}

For charging batteries, a buck converter circuit is used to control voltage levels by switching on/off of the R6030ENZ1 MOSFET using signals from the microcontroller. The MOSFET is driven by the signals of TLP 250, which receives signals from the microcontroller. The signals from the microcontroller is not able to drive the MOSFET directly since the output of the microcontroller has a voltage up to $5 \mathrm{~V}$ which cannot drive the MOSFET. For this reason, the TLP 250 is used to raise the voltage from $5 \mathrm{~V}$ to $10 \mathrm{~V}$. A inductor of $310 \mu \mathrm{H}$ and a capacitor of $330 \mu \mathrm{F}$ are used to control output voltage quality as shown in Fig. 3.

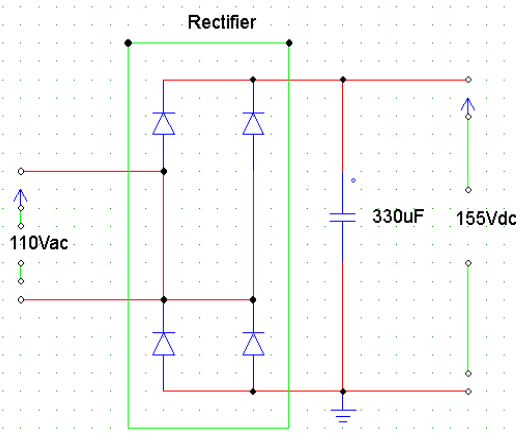

Fig. 2. The circuit diagram of a rectifier.

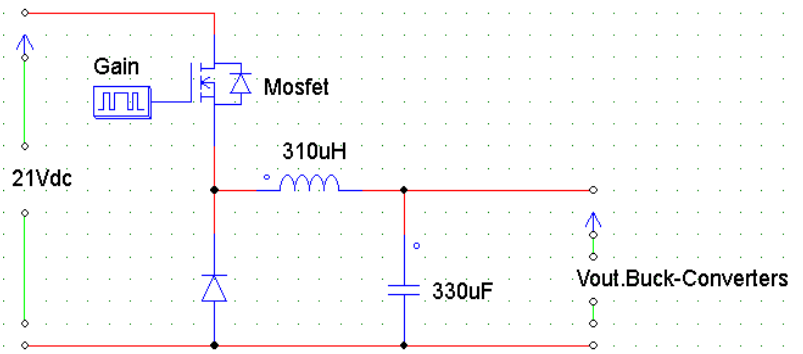

Fig. 3. The circuit diagram of a rectifier.

\subsubsection{Sensor}

A sensor is used to detect voltage and current values in real time. The detected values are sent to the microcontroller, and then they are calculated and processed to signal to drive the MOSFET. The ACS712 $20 \mathrm{~A}$ is selected - . The output ratio between current and voltage is $1 \mathrm{~A}: 100 \mathrm{mV}$. Additionally, if the current is 0 A, the voltage will be $2.5 \mathrm{~V}$ as shown in Fig. 4.

\subsubsection{The control circuits}

The rectifier is used to convert alternating current (AC) to direct current (DC) to charge batteries. The Silicon Bridge rectifier of RBV2500D - RBV2510D is used to convert the $\mathrm{AC}$ voltage of $110 \mathrm{~V}$ from the transformer into DC voltage of $155 \mathrm{~V}$. A $330 \mu \mathrm{F}$ capacitor is employed to reduce the ripple from the bridge rectifier signal to provide DC voltage with constant values as shown in Fig. 2.

\subsection{The control circuits}

A control circuit receives data from the power circuit, making a process in order to send signals to execute MOSFET switching, and control voltage and current. In this case study, there is an LCD display to show operation status. 


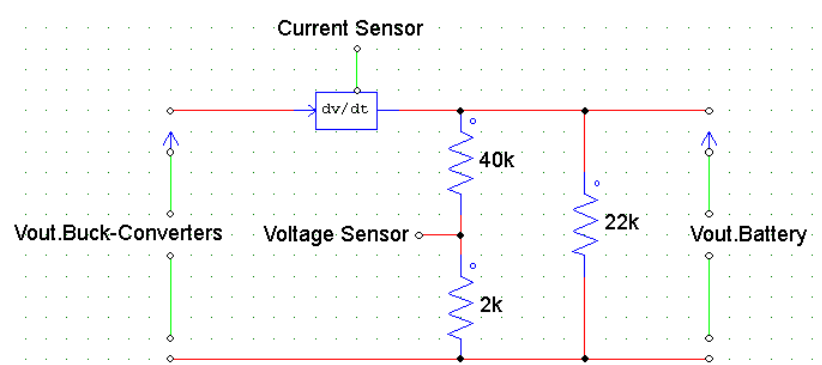

Fig. 4. The circuit diagram of a sensor used to detect current and voltage values.

\subsubsection{A transformer of a control circuit}

The low voltage transformer is used to control voltage to supply a microcontroller and a gate driver. In order to eliminate error processing and disturbed signals of microcontroller operation, the microcontroller circuit is separated from the gate driver and the power circuit by using the transformer. The transformer ratio of 200: 15 is used for the microcontroller circuit, and another transformer in the same ratio is used for the gate driver.

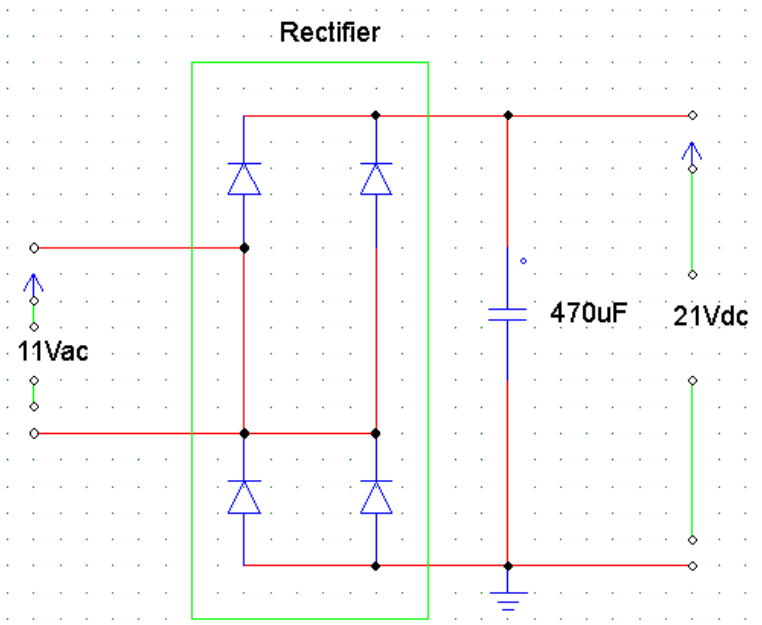

Fig. 5. The circuit diagram of a rectifier of control circuit.

\subsubsection{A rectifier of a control circuit}

he rectifier is used to convert alternating current (AC) to direct current (DC) to supply the microcontroller. The Silicon Bridge rectifier of RBV2500D - RBV2510D is used to convert the AC current of $15 \mathrm{~V}$ to the $\mathrm{DC}$ current of $21 \mathrm{~V}$. The capacitor of $470 \mu \mathrm{F}$ is employed to reduce the ripple from the bridge rectifier signal to provide DC voltage with constant values as shown in Fig. 5.

\subsubsection{A microcontroller}

A microcontroller is a device used to calculate and process the data in order to control system operation. The IC numbers of 7812 and 7805 are used to reduce DC current from $15 \mathrm{~V}$ to $5 \mathrm{~V}$ to supply the microcontroller.
The 7812 IC is employed to prevent overheat conditions of the 7805 IC while the system is operated for a long time. The PIC18F4550 microcontroller is used for calculation and processing of the system operation as shown in Fig. 6.

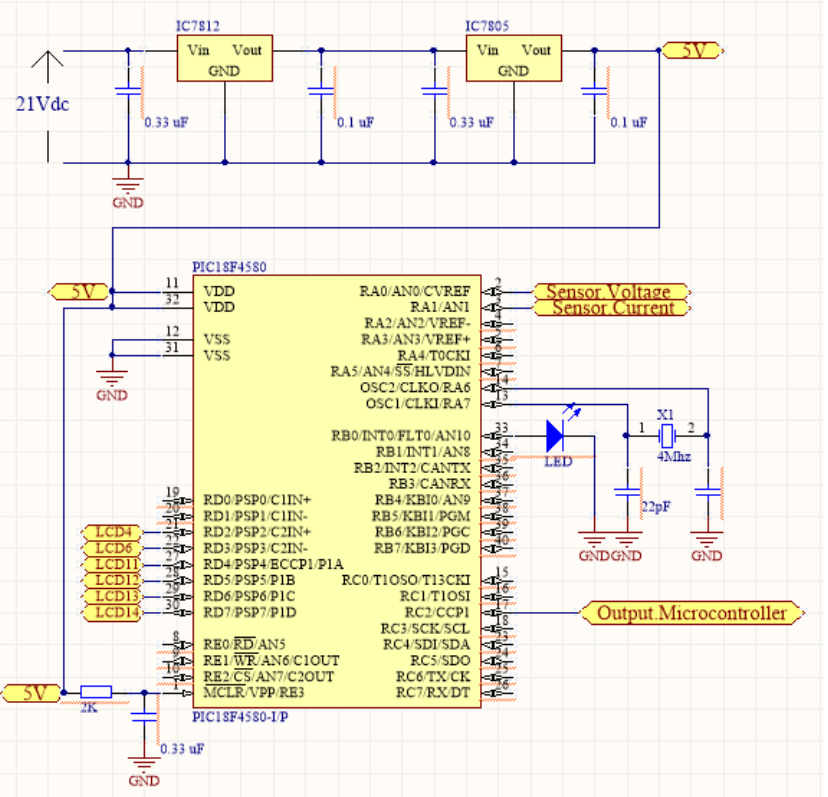

Fig. 6. The circuit diagram of a microcontroller

\subsubsection{A gate driver}

Generally, the switch in the system requires a voltage value in the range of $10 \mathrm{~V}$. By contrast, the voltage value generated from the microcontroller is between 0 to $5 \mathrm{~V}$. For this reason, the TLP 250 is needed to drive the gate ordered by the microcontroller as shown in Fig. 7.

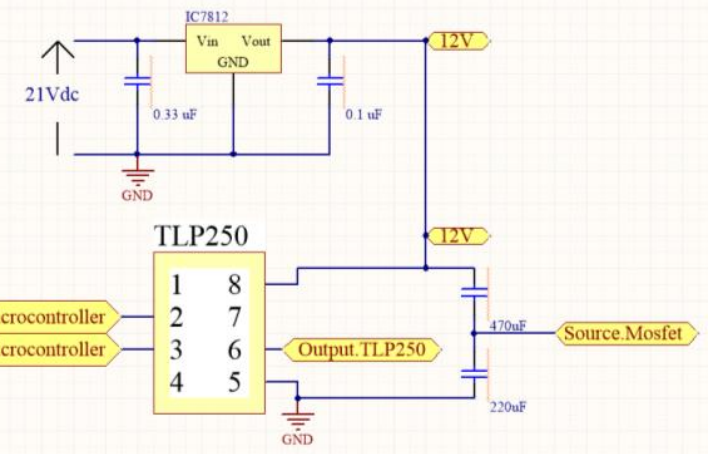

Fig. 7. The circuit diagram of a gate driver

\section{Result}

In the experiment, the voltage and current of battery charging are measured to test both the proposed power circuit and control circuit. The experimental results are divided into two modes: the charge of a constant current mode and the charge of a constant voltage mode as depicted in Fig. 8. 


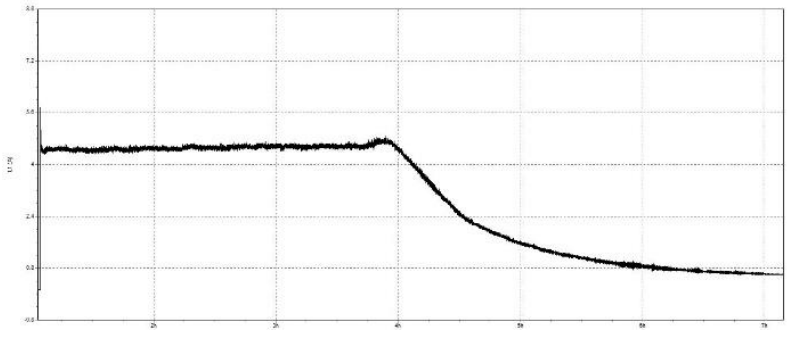

(a) Current

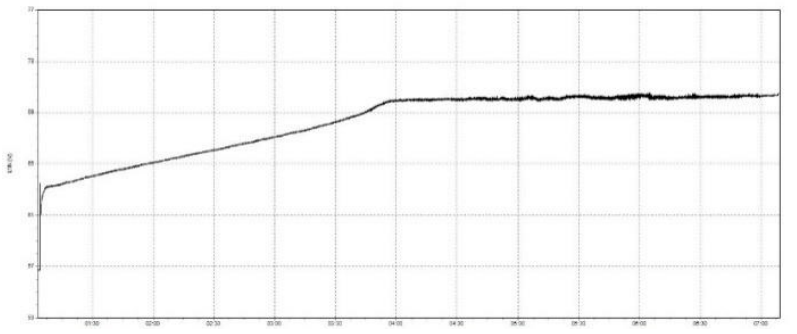

(b) Voltage

Fig. 8. The charge of an electric motorcycle battery at various times.

Fig. 8 presents the behaviour of current and voltage during the charge of the electric motorcycle. The microcontroller can control the MOSFET operation to maintain the current of $4 \mathrm{~A}$. The battery charging process is divided into two states: firstly, the constant current state is controlled by switching of the MOSFET to maintain the current of $4 \mathrm{~A}$, until the voltage of the battery is $72 \mathrm{~V}$. Secondly, the constant voltage state of 72 $\mathrm{V}$ is implemented while the current is decreased until the battery is full.

\section{Conclusion}

This paper presents the design of battery charger for an electric motorcycle. The AC voltage from a residence is used to charge the batteries through the designed charge circuit-it is used to convert the AC voltage to the DC voltage and control the voltage values suitable for the charge process in all periods. From Fig. 8, it shows that the initial charge has the voltage about $55-57 \mathrm{~V}$, and the current is fixed at $4 \mathrm{~A}$. Thus, the duty cycle is adjusted to control the switching of the MOSFET. For this reason, the current and voltage of battery charging are maintained by $4 \mathrm{~A}$ and $72 \mathrm{~V}$ with a charging time of about $6-8$ hours. The switching circuit of TLP 250 can operate normally as switched on and off as required by the microcontroller. It can control the steady current of $4 \mathrm{~A}$ and maintain the voltage level during the charging. However, there is a slight ripple of voltage and current caused by the switching operation.

\section{References}

1. M. Yilmaz, and P. T. Krein, "Review of Battery Charger Topologies, Charging Power Levels, and Infrastructure for Plug-In Electric and Hybrid Vehicles," IEEE Trans. Power Electronics, Vol. 28, No. 5, pp. 2151 -2169, May 2012.

2. F. Musavi, M. Craciun, D.S. Gautam, W. Eberle, W.A. Dunford, "An LLC resonant DC-DC converter for wide output voltage range battery charging applications," IEEE Trans. on Power Electronics, vol. 28, pp. 5437-5445, March 2013.

3. J. Deng, S. Li, S. Hu, C.C Mi, R. Ma, "Design methodology of LLC resonant converters for electric vehicle battery chargers," IEEE Trans. On Vehicular Technology, vol. 63, pp. 1581-1592, May 2014.

4. A. Khaligh, S. Dusmez, "Comprehensive Topological Analysis of Conductive and Inductive Charging Solutions for Plug-In Electric Vehicles," IEEE Trans. Vehicular Technology, Vol. 61, No. 8, pp. 3475 -3489, October 2012.

5. S. F. Tie, C. W. Tan, "A Review of Energy Sources and Energy Management System in Electric Vehicles," Renewable and Sustainable Energy Reviews, Vol. 20, pp. 82-102, 2013.

6. Huaibao Wang, Xiaoyu Jia, J. Li, X. Guo, B. Wang and Xiaoyu Wang, "New single-stage EV charger for V2H applications," 2016 IEEE 8th International Power Electronics and Motion Control Conference (IPEMC-ECCE Asia), Hefei, 2016, pp. 2699-2702.

7. M. C. Kisacikoglu, "Vehicle-to-grid (V2G) reactive power operation analysis of the EV/PHEV bidirectional battery charger," Ph.D. dissertation, Dept. Elect. Eng. Comput. Sci., Univ. Tennessee, Knoxville, TN, USA, 2013.

8. T. Tanaka, T. Sekiya, H. Tanaka, M. Okamoto, and E. Hiraki, "Smart charger for electric vehicles with power-quality compensator on singlephase threewire distribution feeders," IEEE Trans. Ind. Appl., vol. 49, no. 6, pp. 2628-2635, Nov./Dec. 2013.

9. V. Monteiro et al., "Assessment of a battery charger for electric vehicles with reactive power control," in Proc. Ind. Electron. Conf. (IECON), Montreal, QC, Canada, 2012, pp. 5142-5147.

10. M. Kesler, M. C. Kisacikoglu, and L. M. Tolbert, "Vehicle-to-grid reactive power operation using plug-in electric vehicle bidirectional offboard charger," IEEE Trans. Ind. Electron., vol. 61, no. 12, pp. 6778-6784, Dec. 2014.

11. M. C. Kisacikoglu, M. Kesler, and L. Tolbert, "Single-phase on-board bidirectional PEV charger for V2G reactive power operation," IEEE Trans. Smart Grid, vol. 6, no. 2, pp. 767-775, Mar. 2015. 